\title{
Análise da carreira desportiva de atletas das regiões sul e sudeste do Brasil. Estudo dos resultados desportivos nas etapas de formação
}

\author{
Cristina Cafruni ${ }^{1}$ \\ António Marques ${ }^{2}$ \\ Adroaldo Gaya ${ }^{3}$
}

https://doi.org/10.5628/rpcd.06.01.55

\author{
${ }^{1}$ Faculdades Integradas Facvest \\ Curso de Educação Física \\ Lages, SC \\ Brasil \\ ${ }^{2}$ Universidade do Porto \\ Faculdade de Desporto \\ Portugal \\ ${ }^{3}$ Universidade Federal do Rio Grande do Sul \\ Escola Superior de Educação Física \\ Porto Alegre \\ Brasil
}

\section{RESUMO}

\begin{abstract}
A exigência de resultados elevados em desportistas em processo de formação tem sido amplamente questionada na literatura. De acordo com os especialistas, os resultados só devem ser valorizados na última das três etapas do período de formação. Com efeito, a utilização de estratégias tendo em vista a obtenção de resultados nas fases iniciais prejudicaria a obtenção de resultados elevados na etapa de alto rendimento. Neste sentido, o objetivo principal deste estudo foi verificar se atletas que atingiram resultados elevados no desporto de alto nível já apresentavam resultados relevantes durante os períodos de formação. A amostra foi constituída por 165 atletas de alto nível, das regiões sul e sudeste do Brasil, que faziam desporto em seis modalidades - ginástica olímpica, ginástica rítmica, natação, tênis, voleibol e futsal. A informação sobre os resultados obtidos durante as três etapas da formação desportiva propostas por Platonov, foi recolhida através de consultas às federações e da aplicação de um questionário aos atletas. O estudo permitiu concluir que: a) os atletas demonstraram um baixo percentual $(27,5 \%)$ de altos resultados na primeira etapa, um percentual acima do esperado $(67,3 \%)$ na segunda etapa, e um elevado percentual $(87,3 \%)$ na terceira etapa; b) a comparação entre as modalidades revelou diferenças significativas $(p<0,05)$ na primeira e na segunda etapas, todavia, na terceira etapa, os resultados indicaram grande relevância em todos os desportos.
\end{abstract}

Palavras-chave: treino, competição, crianças e jovens, resultados desportivos, treinamento a longo prazo.

\section{ABSTRACT}

The Importance of Sport Results During the Long-Term's Athlete Development. A Study with High Level Brazilian Athletes

The demand for high performances in young athletes is broadly questioned in literature. According to training experts, results should be understood as relevant only during the last stage of the long-term's athlete development. The use of strategies focused on results during the initial stages of the long-term's athlete development may reduce the possibilities of achieving good results during the advanced stages of high level sport. Therefore, the main purpose of this study was to verify, retrospectively, if high level athletes did present relevant results during the initial phases of training and competition. Sample size consisted of 165 high-level Brazilian athletes of Olympic gymnastics, rhythmic gymnastics, swimming, tennis, volleyball, and indoor soccer. Information concerning the results during the three phases of the longterm's athlete development was obtained by consulting sport federations documents and through a questionnaire. We concluded that a) athletes showed a low percentage $(27,5 \%)$ of relevant results during the first stage of their training process, higher than hypothesized percentage $(67,3 \%)$ during the second stage, and an highest percentage $(87,3 \%)$ during the third stage; $b)$ comparison between sports revealed significant differences $(p<0,05)$ during the first and the second stages; c) during the third stage, competitive results presented high relevance for all sports.

Key Words: training, competition, children and youth, sports results, long-term's athlete development. 


\section{INTRODUÇÃO}

É consensual a idéia de que a carreira dos atletas deve ser fruto de um planejamento extremamente minucioso, onde os resultados absolutos estão no ápice dos objetivos $(25,26,39)$. As questões inerentes a este planejamento estão diretamente relacionadas ao percurso do jovem atleta e envolvem, entre outros fatores, o treinamento e as competições. Um erro nesta preparação pode refletir-se posteriormente nos resultados obtidos pelos atletas (30). O período entre a iniciação desportiva e o desporto de alto rendimento é designado pela teoria do treinamento desportivo como um período de formação, onde se procura desenvolver bases que permitam aos atletas alcançar, futuramente, os tão esperados resultados. A chamada "Preparação Desportiva a Longo Prazo" (PDLP), explorada por diversos autores, tem como objetivos principais promover a elevação progressiva das exigências do treinamento, de maneira a obter uma melhora constante da capacidade de rendimento, e obter a máxima eficiência em uma determinada idade (44).

Nos modelos de PDLP estudados, são estabelecidas várias etapas de treinamento, cada qual com objetivos pré-definidos. Com alguma variação em relação ao número de etapas $(43)$, a maioria dos autores (3, $6,15,19,26,31,32,37,47)$ estabelece esta divisão em três fases precedentes ao alto rendimento. Para cada etapa, é determinada uma margem de idade que varia conforme o desporto e o sexo. $\mathrm{Na}$ abordagem da PDLP a preocupação com a obtenção de altos resultados (AR) só deve iniciar-se na última fase da formação desportiva, a terceira etapa, e culmina na fase do alto rendimento $(6,15,26,32,37,44,47)$. No entanto, muitas vezes estas orientações aparentam ser contraditórias com a prática.

Freqüentemente, tem-se assistido a um tratamento de iguais proporções: pequenos atletas são treinados para campeonatos mirins e infantis como se dependessem destas vitórias para o sucesso futuro. E, muitas vezes, se faz dos jovens campeões um prognóstico para repetir o sucesso na categoria adulta, quando não menos de uma década os separa desta. Esta sobrevalorização dos resultados dos jovens atletas faz-nos questionar a sua validade (38). Se os modelos de preparação deixam explícito que resultados significativos só devem surgir a partir da categoria imediatamente anterior ao alto rendimento, será que existe algum sentido deles ocorrerem antes?
A preocupação em evitar-se os AR prematuros nos jovens ocorre devido às conseqüências que estes podem trazer à carreira do atleta. Por serem geralmente fruto de uma preparação forçada $(25,47)$, os AR adquiridos pelos atletas no período de formação são objeto de duas críticas principais: a primeira, é a possibilidade de provocarem um esgotamento precoce das reservas de adaptação do jovem atleta $(7,37)$ e, a segunda, relaciona-se com a ausência do trabalho de base essencial para se obterem resultados de alto nível na idade adulta, devido à orientação exclusiva para as vitórias durante o processo de formação $(11,34,28,45)$. São duas situações indesejáveis, por possibilitarem ora uma estabilização dos resultados antes das categorias adultas (47), ora uma carreira desportiva reduzida (4).

$\mathrm{Na}$ abordagem deste tema, observamos que poucos estudos evidenciam a associação entre os elevados graus de exigência precoce e as influências que estes podem provocar na carreira dos atletas. Um exemplo é a pesquisa de Barynina e Vaitsekhovskii (4), onde se demonstra que os nadadores que se especializaram mais cedo permaneceram um tempo menor no desporto de alto rendimento. $\mathrm{Na}$ investigação de Paes (36) somente $25 \%$ de uma amostra de basquetebolistas de elite $(n=27)$ iniciaram antes dos 12 anos de idade, indicando, obviamente, que antes desta faixa etária os atletas não obtiveram resultados em competições. Um estudo de caso sobre a trajetória de um talento desportivo demonstrou que o progresso do atleta foi gradativo, sem recordes em categorias inferiores (43). Na pesquisa de Brito et al. (8), embora ainda em andamento, evidencia-se que apenas um reduzido número de atletas que se destacaram em categorias inferiores no atletismo conseguiu reproduzir os mesmos resultados na categoria sênior. Contudo, a literatura desportiva ainda necessita de dados empíricos que nos permitam uma maior compreensão do problema, de maneira a dar aos resultados a importância que eles merecem. Faz-se necessário uma maior reflexão sobre o direcionamento do treinamento de crianças e jovens que participam de programas no desporto de rendimento, uma vez que a orientação adequada é determinante para se atingir o desporto de alto rendimento.

O objetivo principal desta investigação foi verificar se os atletas dos desportos estudados, nomeadamente ginástica olímpica, ginástica rítmica, natação, tênis, voleibol e futsal apresentaram AR enquanto 
pertenciam às categorias iniciais de formação desportiva. Em um segundo momento, objetivou-se: a) observar as manifestações dos AR por modalidade em cada etapa da PDLP; b) analisar a manifestação dos resultados, inferindo a partir de que momento eles podem auxiliar no prognóstico da carreira dos atletas. Este estudo contempla os atletas do sul e sudeste do Brasil, por constituirem regiões de expressividade no desporto nacional.

\section{MATERIAL E MÉTODOS}

\section{Amostra}

A amostra do presente estudo foi constituída por 165 atletas das regiões sul e sudeste do Brasil. São todos desportistas que se destacaram nas competições nacionais mais importantes entre os anos de 1998 e 2002 . Com o cuidado de não incluir na amostra atletas que ainda não fizessem parte do último estágio de preparação desportiva, adotou-se o limite mínimo de idade (LMI) estabelecido por Platonov (37) na última fase de preparação, a etapa de realização dos máximos resultados.

A distribuição dos atletas por modalidade foi a seguinte: Ginástica Olímpica n=17; Ginástica Rítmica $n=10$; Natação $n=69$; Tênis $n=16$; Voleibol $n=40$ e Futsal $n=13$. Cabe salientar que $62 \%$ da amostra foi composta por atletas de seleção nacional, caracterizando desportistas de nível elevado.

\section{Definição de critérios para determinar os altos resultados (AR) nas etapas de formação} Conforme o objetivo principal deste estudo, foi necessário estabelecer critérios que permitissem considerar os resultados mais significativos nas categorias de formação de cada desporto, a fim de identificar os atletas que obtiveram altos rendimentos. Para este fim, foram consultados cinco treinadores de cada modalidade, que satisfizessem a condição de participar e vivenciar, juntamente com seus atletas, os campeonatos estaduais e nacionais. A estes treinadores perguntámos quais os resultados que permitem diferenciar os jovens atletas, permitindo-lhes ocupar uma posição de destaque no meio desportivo. Em outras palavras, buscámos aqueles resultados que se diferenciam da média e que, de certa maneira, obrigam a que os atletas sejam sujeitos a um treino intensivo, com objetivo de alcançar determinada colocação. De acordo com os pareceres dos peritos, e utilizando o método de validação por consenso, foi possível estabelecer os critérios descritos no quadro 1 .

Quadro 1: Critérios adotados para a definição de altos resultados desportivos nas etapas de formação.

\begin{tabular}{|c|c|}
\hline Desporto & Critério \\
\hline \multirow[t]{2}{*}{ Ginástica Olímpica } & Até a $6^{\mathrm{a}}$ colocação no Campeonato \\
\hline & Brasileiro Infantil, Infanto-Juvenil e Juvenil. \\
\hline \multirow[t]{2}{*}{ Ginástica Rítmica } & Até a $6^{a}$ colocação no Campeonato \\
\hline & Brasileiro Infantil, Infanto-Juvenil e Juvenil. \\
\hline \multirow[t]{2}{*}{ Natação } & Até a $8^{\mathrm{a}}$ colocação no Campeonato \\
\hline & Brasileiro Infantil, Juvenil e Júnior. \\
\hline \multirow[t]{2}{*}{ Tênis } & Até a $10^{\mathrm{a}}$ colocação no Ranking Brasileiro \\
\hline & Infanto-Juvenil. \\
\hline \multirow[t]{3}{*}{ Voleibol } & Campeonatos estaduais: até a $3^{a}$ colocação \\
\hline & e/ou Convocações para seleções estaduais \\
\hline & e nacionais. \\
\hline \multirow[t]{3}{*}{ Futsal } & Campeonatos estaduais: até a $3^{a}$ colocação \\
\hline & e/ou Convocações para seleções estaduais \\
\hline & e nacionais. \\
\hline
\end{tabular}

A diferenciação dos critérios entre as modalidades deve-se à heterogeneidade dos desportos, uma vez que cada um possui uma diferente realidade com relação aos campeonatos infanto-juvenis. Podemos observar que em algumas categorias de alguns desportos, por exemplo, não existem muitas equipes participando dos campeonatos, o que torna relativamente fácil se manter no topo das colocações. Por este motivo, os treinadores da Natação, Ginástica Olímpica e Ginástica Rítmica utilizaram-se de critérios referenciados a campeonatos nacionais. Já os treinadores do Voleibol e do Futsal alargaram os critérios, abrangendo também as três primeiras colocações em campeonatos estaduais, por entenderem que estes campeonatos são de um nível elevado nos estados os quais pertencem os atletas da amostra.

\section{Delimitação das idades entre as etapas da PDLP}

Para a comparação entre os AR durante as etapas da PDLP utilizámos o modelo de Platonov (37). Como esta proposta não apresentou as modalidades Voleibol e Tênis, para o primeiro utilizaram-se as mesmas idades do Handebol, e para o segundo adotou-se o modelo de Bompa (6) (Quadro 2). O procedimento consistiu em verificar se os atletas, quando estavam na faixa etária de cada etapa, atingiram o critério pré-estabelecido que representa AR. 
Quadro 2: Delimitação das idades entre as etapas da PDLP. Adaptado de Platonov (1994] e Bompa (2000).

\begin{tabular}{lccc} 
Desporto & $1^{\mathrm{a}}$ etapa & $2^{\mathrm{a}}$ etapa & $3^{\mathrm{a}}$ etapa \\
\hline Ginástica Olímpica (fem./masc.) & $6-8 / 8-10$ anos & $9-10 / 11-13$ anos & $11-13 / 14-15$ anos \\
Ginástica Rítmica (fem.) & $6-8$ anos & $9-10$ anos & $11-13$ anos \\
Natação (fem./masc.) & $8-11 / 9-13$ anos & $12-14 / 14-16$ anos & $15-16 / 17-18$ anos \\
Tênis (fem./masc.) & $6-11 / 6-12$ anos & $12-14 / 13-15$ anos & $15-17 / 16-18$ anos \\
Voleibol (fem./masc.) & $11-14 / 12-15$ anos & $15-16 / 16-18$ anos & $17-19 / 19-20$ anos \\
Futsal (masc.) & $11-15$ anos & $16-18$ anos & $19-20$ anos
\end{tabular}

\section{Coleta de dados}

Os dados que se referem aos resultados dos atletas de Ginástica Olímpica, Ginástica Rítmica, Natação e Tênis foram obtidos com ajuda das respectivas federações e confederações. Através da análise de documentos oficiais dos campeonatos, foi possível verificar as colocações dos atletas.

Como os critérios para os AR do Voleibol e do Futsal implicavam em informações sobre os campeonatos estaduais e, portanto, percorrer todo o Brasil, uma vez que os atletas pertenciam a diferentes estados, recorreu-se a outro procedimento. Foi elaborado um questionário com o objetivo de verificar os resultados dos atletas ao longo de suas carreiras e aplicado aos jogadores durante a Superliga de Voleibol/2001 e a Liga Futsal/2002. Para a elaboração deste instrumento utilizou-se o método de validação por consenso entre os especialistas, abrangendo um professor universitário com título de doutor e dois treinadores do desporto específico.

\section{Procedimentos estatísticos}

Para a análise dos AR nas três etapas recorreu-se aos procedimentos da Estatística Descritiva, através da porcentagem de AR em cada etapa da PDLP. O teste do Qui-Quadrado foi utilizado para verificar se o comportamento dos resultados entre as modalidades foi diferente do demonstrado na amostra total. O programa estatístico utilizado foi o SPSS 9.0.

\section{RESULTADOS E DISCUSSÃO}

Percentagem de altos resultados (AR) no conjunto das modalidades desportivas ${ }^{1}$ durante as três primeiras etapas da PDLP
Na Figura 1 observa-se que apenas 27,5\% dos atletas apresentaram AR enquanto pertenciam à primeira etapa de preparação, contra $67,3 \%$ na segunda etapa e $87,3 \%$ na terceira etapa.

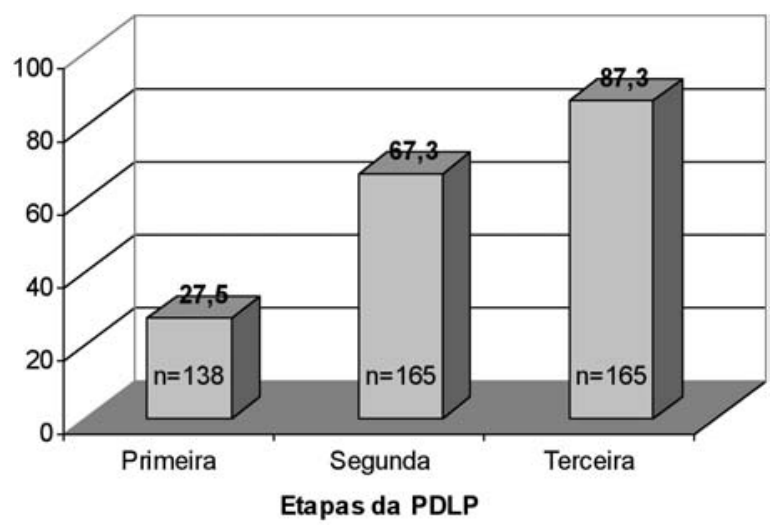

Figura 1: Percentagem de altos resultados nas modalidades desportivas durante as etapas da PDLP.

A primeira observação que nos cabe, em relação aos altos resultados (AR) dos desportistas durante o período de formação, é verificada através da dinâmica ascendente durante as três etapas da preparação desportiva. Neste sentido, confirma-se um dos principais objetivos da PDLP, referido por Weineck (44) e Harre (16), que está resumido na elevação progressiva das exigências do treino, de maneira a obter-se uma melhora constante da capacidade de performance. Martin (31) diz que a estrutura da PDLP deve conter um programa de treino em perspectiva para crianças e jovens, com base na aquisição gradual dos elementos da modalidade praticada. O peso dos resultados nas 
três primeiras etapas da PDLP parece seguir o princípio da especialização crescente, ao tornar-se mais relevante quando se aproxima do alto nível desportivo. O fato de que apenas $27,5 \%$ dos atletas apresentaram altos resultados durante a primeira etapa da PDLP parece demonstrar que a maioria dos desportistas foi orientada de acordo com os objetivos que norteiam esta fase e que, portanto, excluem a exigência da obtenção de resultados $(6,11,31,32,47)$. Durante este período a preocupação deve orientar-se para as tarefas que dizem respeito à formação dos atletas (26), sendo esta subordinada ao treinamento multilateral (31), que não cria condições para o aparecimento de êxitos imediatos (33).

A presente pesquisa encontrou semelhanças com os achados de Paes (36), onde somente $25 \%$ dos atletas da elite do basquetebol brasileiro iniciaram a prática competitiva antes dos 12 anos de idade, embora a pesquisa do autor não tenha se detido à quantificação dos resultados destes atletas. Também está de acordo com estudo de Nagorni (apud Bompa (6), onde os atletas bem sucedidos em categorias adultas não demonstraram ser campeões nacionais quando menores.

No entanto, o grupo de atletas que apresentou altos resultados já na primeira etapa da PDLP atingiu o alto nível posteriormente, contrariando a idéia de que os AR no início do treinamento dos jovens possam impedir os altos rendimentos na idade adulta. É provável que estes atletas constituam exceções já previstas por Platonov (37). Também cabe mencionar que as possíveis diferenças maturacionais apresentadas pelos atletas podem refletir-se nos resultados obtidos (22). Contudo, não possuímos dados substanciais que permitam uma análise mais aprofundada sobre os mesmos.

Quando nos deparamos com os AR durante a segunda etapa da PDLP, representada por $67,3 \%$ dos atletas, consideramos os valores altos em contraste com os objetivos indicados pela PDLP relativos a esta fase. O conteúdo desta etapa é direcionado para o desenvolvimento dos fundamentos básicos da modalidade, e mesmo que este conduza a um aumento da preparação especial, ele não deve ainda ser significante para produzir AR $(5,26,37,47)$. Destacamos, ainda, que a atividade competitiva neste período deve ter um caráter auxiliar e apresentar um programa simplificado $(15,47)$. No entanto, sabemos que os critérios adotados para a definição de AR nesta etapa incluem as primeiras colocações em campeonatos brasileiros e, em alguns casos, estaduais. Estes critérios, por incluírem campeonatos altamente disputados e de bom nível, exigem que o atleta seja orientado para os regulamentos impostos pelo sistema de competições. Em outras palavras, dificilmente o atleta obterá AR se não for exclusivamente preparado para tal, sugerindo que a preparação dos atletas na segunda etapa da PDLP foi predominantemente orientada para a obtenção de AR.

A última etapa da PDLP demonstrou que os atletas apresentaram um elevado percentual de AR, representado por $87,3 \%$ da amostra. Este período da PDLP é marcado por uma especialização aprofunda$\mathrm{da}$, em que o treinamento visa o rendimento em uma atividade competitiva $(5,26,37)$. Neste momento são definidas as orientações referentes às posições ou provas do atleta, e as competições se aproximam ao número das ocorridas durante a última etapa $(32,47)$. Com base nestes princípios, podemos concluir que a maioria dos atletas não se distanciou dos objetivos, ao demonstrarem AR nesta fase. Outro fator que pode explicar a forte presença de AR neste período, é a existência da zona dos primeiros altos êxitos $(15,38)$, que pode ser definida como o momento em que alguns resultados começam a surgir, mesmo que estes não correspondam aos melhores resultados da carreira do atleta.

Ao analisarmos os AR, no sentido de determinar se eles podem significar um prognóstico para o alto nível, podemos conduzir algumas conclusões. Alguns autores referem que muitos atletas adultos não foram campeões quando crianças e jovens $(1,6$, $11,15)$, o que foi amplamente comprovado neste estudo em relação à primeira etapa da PDLP, onde $72,5 \%$ dos desportistas não apresentaram AR. Muitos autores $(6,15,24,26,27,35,41)$ relatam que os resultados de crianças e jovens não são garantia de futuros êxitos. Contudo, poucas pesquisas mencionam o momento a partir do qual os resultados dos jovens atletas podem constituir um instrumento relevante para auxiliar na questão do prognóstico. Em alguns casos verificou-se uma alta corre- 
lação apenas dois anos antes dos resultados absolutos (13), ou na categoria anterior ao alto rendimento (18). Outra situação demonstrou que a proximidade com a categoria adulta aumenta a presença de resultados (7). Concluímos que a presente pesquisa apresentou semelhanças com as referências, ao indicar que $87,3 \%$ dos atletas obtiveram AR na terceira etapa da PDLP, portanto, alguns anos antes da etapa do alto rendimento. Em resumo, podemos dizer que os AR apresentados pelos atletas do nosso estudo, durante a terceira etapa da PDLP, constituem um instrumento importante no auxílio ao prognóstico para o alto nível. Por outro lado, os AR na primeira etapa da PDLP não demonstraram ser relevantes em relação à questão do prognóstico.

\section{Percentagem de altos resultados por desporto durante a primeira etapa da PDLP}

A Figura 2 aponta que o Tênis foi o desporto que apresentou o maior percentual de vencedores $(68,8 \%)$ durante a primeira etapa, seguido do Voleibol $(32,5 \%)$ e da Natação $(20,3 \%)$. Os atletas de Futsal não demonstraram ser vencedores nesta etapa. Salientamos que, nesta fase, a Ginástica Olímpica e a Ginástica Rítmica não realizam campeonatos nacionais, e por este motivo não são realizadas comparações destes desportos.

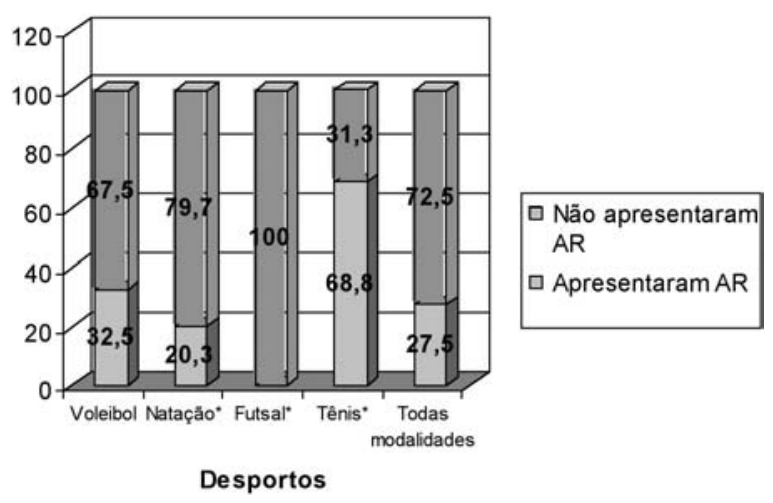

*(diferenças significativas)

Figura 2: Percentagem de altos resultados nas modalidades desportivas durante a primeira etapa da PDLP.
O teste do Qui-Quadrado revelou que a Natação, o Futsal e o Tênis apresentaram diferenças significativas $(p<0,05)$ em relação à amostra total, que engloba o comportamento dos resultados entre todas as modalidades. Entretanto, este comportamento na Natação e no Futsal não demonstrou uma alteração, prevalecendo os desportistas que não apresentaram AR. Apenas sua magnitude superou a da amostra total, ou seja, foram encontrados maiores valores percentuais de atletas que não apresentaram AR. O baixo percentual de AR na Natação $(20,3 \%)$ indica que a maioria dos atletas foi orientada de acordo com os princípios deste período de preparação propostos por Makarenko (23) e Wilke e Madsen (46), em que os objetivos principais valorizam a multilateralidade, a motivação para o desporto e o desenvolvimento das técnicas de nado. Além disso, neste momento as competições têm lugar como instrumento de controle. Os dados da natação sugerem que a preocupação nesta etapa não foi a obtenção de AR, e demonstram concordar com a posição de evitar os altos rendimentos durante a infância, sob o risco de provocar uma futura estagnação e, por conseqüência, o abandono do desporto $(21,46)$. Os dados relativos ao Futsal são curiosos quando comparados aos do outro desporto coletivo desta pesquisa, o Voleibol, que obteve $32,5 \%$ de AR e não apresentou diferenças significativas em relação à amostra total. Um fator que talvez explique esta diferença, é que no Voleibol a necessidade de orientar os jogadores para posições específicas é mais marcante do que no Futsal, onde é mais comum a presença de jogadores polivalentes $(17,42)$. Contudo, o desenvolvimento desta especificidade deve ocorrer entre o final desta etapa e o início da seguinte. Analisando a realidade competitiva do Futsal e do Voleibol, esperar-se-ia valores inversos. Enquanto os campeonatos estaduais de Voleibol (14) ocorrem com a idade mínima de 13 anos, no Futsal eles acontecem aos 7 (SP) e 11 anos (RS). Com $68,8 \%$ de AR, o tênis apresentou diferença significativa $(p<0,05)$ em relação à amostra total, salientando uma mudança no comportamento dos $\mathrm{AR}$, sendo, portanto, a única modalidade desta etapa com predominância de atletas que apresentaram AR. Estes altos valores estão em contraposição com as 
indicações de Cayer e Lamarche (10), pois referem que neste período a preocupação deve estar voltada para a aprendizagem de golpes e a consistência de jogo. Enquanto os autores (op. cit.) salientam, nesta fase inicial, a participação em campeonatos internos, na escola ou no clube, a maioria dos tenistas da amostra já estava classificada entre os dez melhores do ranking nacional. Segundo Lüdorf (20), é forte a influência do tênis profissional existente entre os pais e crianças praticantes. É possível que esta influência exerça uma cobrança interessante em relação aos campeonatos desde cedo, não proporcionando outra opção senão orientar a vencer.

\section{Percentagem de altos resultados por desporto durante a segunda etapa da PDLP}

A Figura 3 mostra que o Voleibol e o Futsal foram as únicas modalidades que apresentaram diferenças significativas $(p<0,05)$ em relação à amostra total.

Nesta etapa, em que a maioria dos atletas destacouse, apresentando AR (67,3\%), o Futsal diferiu dos demais desportos, ao demonstrar predominância de jovens que não apresentaram AR $(84,6 \%)$.

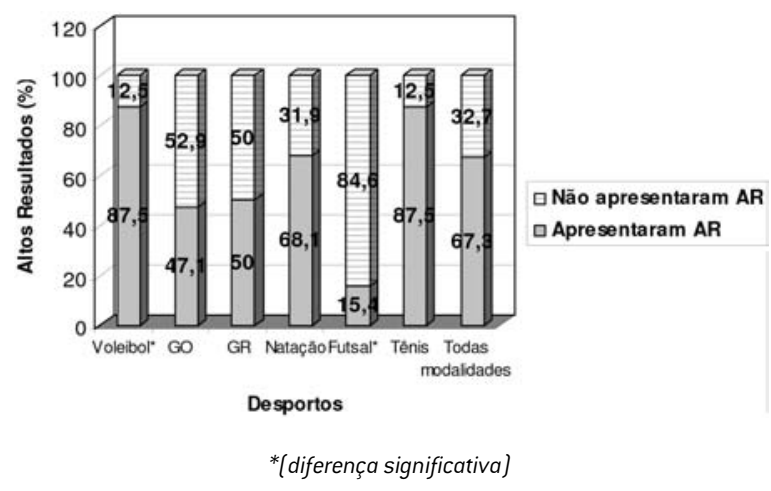

Figura 3: Percentagem de altos resultados nas modalidades desportivas durante a segunda etapa da PDLP.

Os altos percentuais obtidos pelo Voleibol demonstraram uma proximidade muito grande com a terceira etapa. Em outras palavras, a relevância dos AR para esta modalidade na segunda e terceira etapas revelou-se similar, discordando da ocorrência de uma melhora gradual do treinamento (31) e, por conseqüência, da performance.
No voleibol a segunda etapa da PDLP coincide com o início da especialização nas posições (9) e com a primeira "categoria de base" das seleções nacionais, a infanto-juvenil (12). As categorias de base são acompanhadas pela Confederação Brasileira de Voleibol, visto que possivelmente farão a sucessão das equipes adultas. É provável que estes fatores influenciem, já nesta etapa, na orientação para os altos rendimentos.

O período referente à segunda etapa da PDLP do tênis é considerado por Cayer e Lamarche (10) uma fase de transição, com ênfase no treinamento multilateral e na participação em competições regionais. Discordando, portanto, do alto percentual de AR $(87,5 \%)$ encontrado neste desporto.

Os dados relativos aos AR da Ginástica Olímpica e Ginástica Rítmica Desportiva surgem pela primeira vez nesta etapa, pois os campeonatos nacionais só ocorrem a partir desta. Encontramos valores percentuais semelhantes $(47,1 \%$ para a GO e $50 \%$ para a GRD), confirmando a proximidade das características do treinamento e regime de competições das duas modalidades. Os autores concordam com as baixas idades no início do treinamento da ginástica (40), mas em nenhum momento mencionam a importância de se obter AR nesta etapa. A participação nas competições é enfatizada como forma de experiência $(3,40)$, discordando, portanto, de aproximadamente metade dos atletas da amostra destas modalidades.

Embora os percentuais dos desportos em geral tenham sido considerados relativamente altos, foi possível observar, nesta etapa, uma maior consistência do comportamento dos AR, uma vez que o Futsal e o Voleibol foram as únicas modalidades que apresentaram diferenças significativas em relação ao conjunto das modalidades.

\section{Percentagem de altos resultados por desporto durante a terceira etapa da PDLP}

$\mathrm{Na}$ terceira etapa de preparação dos desportistas, aquela que antecede o nível do alto rendimento, verificamos que não houve diferenças significativas no comportamento dos AR entre as modalidades e a amostra total (Figura 4). 


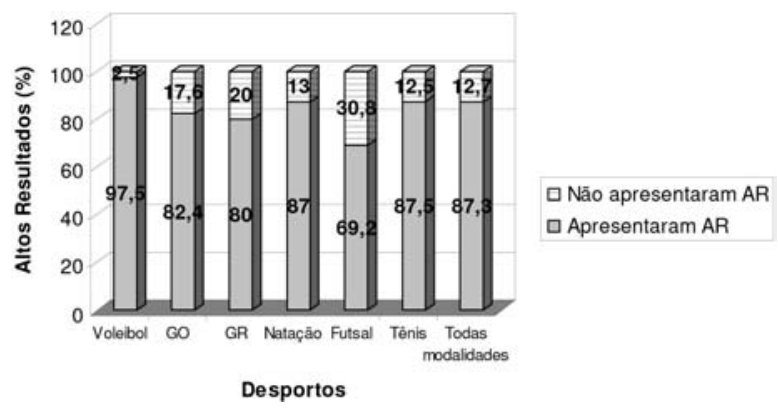

Figura 4: Percentagem de altos resultados nas modalidades desportivas durante a terceira etapa da PDLP.

Nesta etapa, encontramos todas as modalidades com valores percentuais de AR superiores ou próximos da faixa dos $70 \%$. Consideramos que estes altos valores estão de acordo com a previsão da literatura, que refere somente nesta fase da PDLP um aumento expressivo do treino específico e da orientação para a estrutura do alto rendimento $(6,15,26,31,32,37,44,47)$. As diretrizes da literatura especializada mencionam, nesta fase, a forte presença dos campeonatos, sejam estes nacionais ou internacionais. É um período de definição das provas específicas ou de revelação de posições (no caso das modalidades coletivas) (10, $12,23,40)$.

\section{CONCLUSÕES}

A presença de AR na carreira dos 165 atletas das regiões sul e sudeste do Brasil revelou uma maior importância na medida em que estes se aproximaram da categoria adulta. Os dados que se referem à primeira etapa $(27,5 \%$ de $\mathrm{AR})$ e à terceira etapa (87,3\% de AR) da PDLP confirmaram as afirmações da literatura a respeito de quando devem manifestarse os resultados no desporto de crianças e jovens. $\mathrm{O}$ percentual encontrado na segunda etapa, por um lado - em relação à progressão dos AR ao longo das etapas - está de acordo com a literatura. Porém, parece que os valores $(67,3 \%)$ apresentam-se altos demais para os objetivos desta fase.

O comportamento dos AR entre as modalidades revela uma semelhança entre elas, sem diferenças significativas $(p<0,05)$, apenas na terceira etapa da PDLP. Nas duas primeiras etapas, as modalidades revelaram um comportamento diverso em relação aos AR.
A última etapa da PDLP parece constituir um importante instrumento no auxílio ao prognóstico de altos rendimentos nas categorias adultas. O mesmo não pode se afirmar em relação à primeira etapa da PDLP, pois a maioria dos atletas da amostra $(72,5$ \%) não apresentou AR neste período.

Uma alternativa para estudos posteriores seria a realização de registros diretos da performance ao longo das etapas, com amostras mais extensas de cada desporto, o que permitirá uma comparação mais precisa.

\section{NOTA}

(1) Ginástica Olímpica e a Ginástica Rítmica não participaram da análise referente à $1^{\mathrm{a}}$ etapa, devido à ausência de campeonatos de caráter nacional neste período.

\section{AGRADECIMENTOS}

O resumo do presente artigo foi publicado nos seguintes anais:

- $16^{\circ}$ Congresso Brasileiro de Medicina do Esporte, 2003, Costão do Santinho (Revista Brasileira de Medicina do Esporte. São Paulo: Redprint, 2003. v.9. p.4).

- $10^{\circ}$ Congresso de Ciências do Desporto e de Educação Física dos Países de Língua Portuguesa (Revista Portuguesa de Ciências do Desporto (2004). Porto: Faculdade de Ciências do Desporto e de Educação Física, v.4, p.218.)

\section{CORRESPONDÊNCIA}

\section{Cristina Cafruni}

Rua Marquês do Pombal, 917 ap. 201

90540-001 Porto Alegre - RS

BRASIL

ccafruni@hotmail.com 


\section{REFERÊNCIAS BIBLIOGRÁFICAS}

1. Anderson D, Magill R (1996). Critical Periods as Optimal Readiness for Learning Sports Skills. In Smoll F, Smith R. Children and youth in sport. A biopsychosocial perspective. McGraw-Hill, 57-71.

2. Araújo C (1998). O treino dos jovens ginastas. Horizonte $\mathrm{XV}(85): 1-12$.

3. Barbanti V (1997). Teoria e prática do treinamento esportivo. São Paulo: Edgard Blücher.

4. Barynina I, Vaitsekhovskii SM (1992). The afthermath of early sports specialization for highly qualified swimmers. Fitness and Sports Review International 27(4):132-134.

5. Bompa T (1999). Periodization. Theory and Methodology of Training. 4.ed. Champaign, IL: Human Kinetics.

6. Bompa T (2000). Total Training for Young Champions. Champaign, IL: Human Kinetics.

7. Brito N, Fonseca A, Rolim R (2004). Os melhores atletas nos escalões de formação serão igualmente os melhores atletas no escalão sénior? Análise centrada nos rankings femininos das diferentes disciplinas do Atletismo ao longo das últimas duas décadas em Portugal. Revista Portuguesa de Ciências do Desporto 4(1):17-28.

8. Cafruni C (2003). Análise da Carreira Desportiva de Atletas Brasileiros. Estudo da relação entre o processo de formação e o rendimento desportivo. Dissertação de Mestrado. Faculdade de Ciências do Desporto e de Educação Física. Universidade do Porto, Portugal.

9. Cardinal C (2001). Treinamento técnico-tático. In Filho C, Aquino EJV (2001). Voleibol: curso de treinadores nível II. Porto Alegre: Confederação Brasileira de Voleibol.

10. Cayer L, Lamarche P (1989). Modelo de desarrollo especifico para el tenis. VI Simposium para entrenadores de la Federación Internacional de Tenis. Madrid: Escuela Nacional de Maestria de Tenis, 44-105.

11. Coelho O (2000). Pode a passada ser maior que a perna? In Garganta J (ed.) Horizontes e órbitas no treino dos jogos desportivos. Faculdade de Ciências do Desporto e de Educação Física. Universidade do Porto, Portugal, 145-154.

12. Costa PMNC (1998). Formação das seleções básicas no voleibol brasileiro. Brasília: Instituto Nacional do Desenvolvimento do Desporto.

13. Durand M (1987). L'enfant et le sport. Paris: Presses Universitaires de France.

14. Federação Gaúcha de Voleibol (2002). Regulamento de 2002. Porto Alegre.

15. Filin VP (1996). Desporto Juvenil: Teoria e Metodologia. Londrina: CID.

16. Harre D (1982). Principles of Sports Training. Introduction to the theory and Methods of Training. Berlin: Sportverlag.

17. Júnior NB (1998). A ciência do esporte aplicada ao futsal. Rio de Janeiro: Sprint.

18. Kobjakov JUP (1994). Sur la possibilité de prognostiquer les résultats sportifs et certain des indices morphologiques des jeunes gymnastes. In Ganzin M. Gymnastique artistique et G.R.S. Comunications scientifiques et techniques d'experts étrangers. Paris: INSEP, 69-76.

19. Lima T (1988). A formação desportiva dos jovens. Horizonte 25:21-26.

20. Lüdorf SMA (1999). Tênis para crianças: uma abordagem científico-pedagógica. Kinesis 21: 207-222.

21. Maglischo EW (1990). Nadar más rapido. Tratado completo de natación. 2.ed. Barcelona: Hispano Europea.
22. Maia J (2000). Exigências precoces de alto rendimento desportivo nos jogos desportivos. In Garganta J (ed.) Horizontes e órbitas no treino dos jogos desportivos. Universidade do Porto, Faculdade de Ciências do Desporto e de Educação Física,133-143.

23. Makarenko LP (2001). Natação: seleção de talentos e iniciação desportiva. Porto Alegre: Artmed.

24. Malina RM (1986). Readiness for Competitive Sport. In Weiss M, Gould D Sport for Children and Youths. The 1984 Olympic Scientific Congress Proceedings. Champaign, Illinois: Human Kinetics Publishers X: 45-50.

25. Marques A (1991). A Especialização Precoce na Preparação Desportiva. Treino Desportivo 19: 9-15.

26. Marques A (1993). A periodização do treino em crianças e jovens. Resultados de um estudo nos centros experimentais de treino da Faculdade de Ciências do Desporto e de Educação Física da Universidade do Porto. In Marques A, Bento J (eds.) As Ciências do Desporto e a Prática Desportiva. Universidade do Porto, Faculdade de Ciências do Desporto e de Educação Física, 243-257.

27. Marques A (1999). Crianças e Adolescentes Atletas: entre a Escola e os Centros de Treino ... entre os Centros de Treino e a Escola! In CEFD (Ed.) Treino de Jovens. Lisboa: IND, 17-30.

28. Marques A (2000). Sobre as Questões da Qualidade no Treino dos Mais Jovens. In Silva FM (Org.) Produção do Conhecimento no Treinamento Desportivo. Pluralidade e Diversidade. João Pessoa: UFPB, 51-59.

29. Martin D, Klaus C, Klaus L (2001). Manual de Metodología del Entrenamiento Deportivo. Barcelona: Paidotribo.

30. Martin D, Krug J, Reib M, Rost K (1997). L'Evoluzione del Sistema di Allenamento e di Gara nello Sport di Vertice e Conseguenze per il Ciclo Olimpico 1996-2000. SdS/Rivista di Cultura Sportiva 37:16-25.

31. Martin D (1999). Capacidade de Performance e Desenvolvimento no Desporto de Jovens. In CEFD (Ed.). Treino de Jovens. Lisboa: IND, 37-59.

32. Matvéiev L (1991). Fundamentos do Treino Desportivo. Lisboa: Livros Horizonte.

33. Mesquita, I (1997). Pedagogia do treino. A formação em jogos desportivos coletivos. Lisboa: Livros Horizonte.

34. Nadori L (1990). Especialización y talento. Problemas pedagógicos de la especialización y de la promoción del talento en el deporte. Stadium 141:41-46.

35. Pereira JG (1999). Treinar jovens: benefícios ou risco? In CEFD (Ed.). Treino de Jovens, Lisboa: IND, 65-69.

36. Paes RR (1997). Aprendizagem e Competição Precoce. O Caso do Basquetebol. 3.ed. Campinas: UNICAMP.

37. Platonov V (1994). I Principi della Preparazione a Lungo Termine. SdS/Rivista di Cultura Sportiva 30: 2-10.

38. Platonov V (2004). Das langfristige trainingssystem endet nicht mit dem Erreichen des Leistungshöhepunkts! Leistungssport 34: 18-22.

39. Rolim R. (2004). O treino de resistência com crianças e jovens. In Gaya A, Marques A, Tani, G Desporto para crianças e jovens. Razões e Finalidades. Porto Alegre: Editora da UFRGS, 429-457.

40. Smoleuskiy V, Gaverdouskiy V (1997). Tratado general de gimnasia artística deportiva. Barcelona: Paidotribo.

41. Sobral F (1994). Desporto Infanto-Juvenil: Prontidão e Talento. Lisboa: Livros Horizonte. 
42. Souza PRC (1999). Proposta de avaliação e metodologia para o desenvolvimento do conhecimento tático em esportes coletivos: o exemplo do futsal. In I Premio Indesp de Literatura Esportiva. Brasília: Indesp, 1: 289-340.

43. Vieira LF, Vieira JLL, Krebs RJ (1999). A trajetória de desenvolvimento de um talento esportivo: estudo de caso. Kinesis 21: 47-55.

44. Weineck J (1999). Treinamento Ideal. 9a ed. São Paulo: Manole.

45. Wiersma L (2000). Risks and Benefits of Youth Sport Specialization: Perspectives and Recommendations. Ped Exerc Sci 12:13-22.

46. Wilke K, Madsen O (1990). El entrenamiento del nadador juvenil. Buenos Aires: Stadium.

47. Zakharov A (1992). Ciência do Treinamento Desportivo. Rio de Janeiro: Grupo Palestra Sport. 